Rev Chil Salud Pública 2012;

Vol $16(3): 282-287$

Traducciones

\section{Epílogo: sexo de los ángeles (en la torre de marfil)*}

\author{
EPILOGUE: SEX OF THE ANGELS (IN THE TOWER OF MARFIL)
}

Cuando el lenguaje metafórico se ubica fuera de la ciencia, se excluye un conjunto de problemas.

Es como tener un trozo de madera para ser cortado, pero el carpintero insiste en usar solo el martillo. Como ese utensilio no conseguirá cortar la madera, él dice para sí mismo, ¿para qué cortar la madera?(...).

Para un carpintero estúpido, sus problemas son aquellos que consigue resolver con las herramientas que sabe utilizar. No comienza mirando alrededor y detectando los problemas. Comienza mirando las herramientas que sabe utilizar

Gonzalo M Tavares

Durante un encuentro informal en una institución de posgraduados en Salud Pública de Río de Janeiro, un grupo de investigadores conversaba amenamente. Se hablaba de las distintas formas de actuar en el campo de la salud pública y se valorizaban iniciativas que involucraban una actuación concreta en comunidades, en detrimento de propuestas académicas más bien críticas de cuño estrictamente teórico. Quien sustentaba ese punto de vista, de hecho, más allá de la capacitación académica en su campo de estudio, también se destacaba por una vigorosa actuación comunitaria fuera de la institución. En el calor del intercambio de ideas este mismo investigador empleó el argumento de la efectividad de la acción práctica en relación a un supuesta inefectividad de la supuesta 'pasividad teórica'. Apeló a una conocida expresión, al enfatizar que no poseía inclinación para 'discutir acerca del sexo de los ángeles'.

Este conocido aforismo resalta una dimensión de menor importancia en la escala de prioridades que tendría una discusión crítica de carácter conceptual en el campo de la salud pública. Claramente, son indiscutiblemente graves las necesidades de salud existentes en una ciudad atribulada por las desigualdades sociales que provocan enormes carencias y precariedades, como es el caso de Río de Janeiro, y que demandan acciones inmediatas y políticas públicas para esto. En este caso, los estudios teóricos que apuntan a una reflexión y a una crítica a los presupuestos que modelan las perspectiva conceptuales de las prácticas sanitarias pueden no tener la misma preeminencia que la acciones que minimizan situaciones graves, como -por ejemplo- las grandes insuficiencias del sistema público de salud en Río de Janeiro.

Sin embargo, vale la pena a pesar de la supuesta poca relevancia práctica, investigar la expresión 'discutir el sexo de los ángeles' que parece tener origen en la época de la invasión de Constantinopla por los turcos en 1453. El

\footnotetext{
(1)Profesor de la Escuela Nacional de Salud Pública, Fiocruz. Río de Janeiro. Brasil. Isdvdcst|@gmail.com
} \\ LUIS DAVID CASTIEL (1)}

\footnotetext{
* Epílogo del libro Das Loucuras da Razão ao Sexo dos Anjos Rio de Janeiro 2011 Editorial Fiocruz. Traducción de Yuri Carvajal y Miguel Kottow, revisada por el autor.
} 
último soberano del Imperio Romano en Oriente, Constantino XI, llevaba una lucha contra los invasores mientras las autoridades eclesiásticas cristianas se dedicaban a intensos debates teológicos en un concilio. Una de ellas era decidir la posibilidad de definir el sexo de las criaturas angelicales, en el sentido de género, es claro.

Más allá de no llegar a ninguna conclusión en el evento, tanto el emperador como un gran número de cristianos murió en el conflicto bélico. Los nuevos conquistadores liderados por Mahoma I ocuparon la ciudad, también conocida como Bizancio. De allí se originaría la expresión "bizantina", para designar una discusión estéril, no productiva, en sentido práctico.

Tales críticas, admitamos, eventualmente, tienen algún grado de razón, pues innegablemente, hay posturas que pueden ser consideradas como un encierro en una torre de marfil. Como se sabe, la expresión 'torre de marfil' designa un espacio privilegiado en el cual los intelectuales se dedican a elaboraciones abstractas y cuestionamientos desconectados de problemas referentes o relacionados a las prácticas cotidianas.

Es evidente la connotación despreciativa del sustantivo 'intelectual' al señalar que su modo usual de ser se constituye en un apartamiento deliberado de las preocupaciones relevantes del día a día, encaradas como triviales, desprovistas de la supuesta importancia atribuida a aspectos considerados menos prosaicos que encontraría abrigo en los dominios teórico-filosóficos.

En la misma cadena de significados, una 'torre de marfil' también se refiere a investigaciones irrazonables, 'hiperespecializadas', en suma, poco útiles en relación a las demandas en el campo de la salud. Y, más, reflejarían la vaguedad y la arrogancia que proliferan en el ambiente académico.

Más allá de esto, es recurrente, en los lugares de investigación y enseñanza de posgrado en salud pública, una crítica equivalente por parte de algunos investigadores vinculados por métodos y protocolos que privilegian una acción instrumental. Ellos descartan la relevancia de discusiones reflexivas/conceptuales, toda vez que tenerlas en consideración, poco o nada aportarían al dominio de las técnicas y proce- dimientos de investigación, especialmente para producir y elaborar proyectos investigativos y las correspondientes publicaciones en artículos.

Esta dicotomía recurrente y, a veces, mal situada entre teoría vs práctica, se mantiene hace varias décadas, pero parece haberse reforzado con el énfasis de la productividad globalizada que predomina en la actualidad.

Una ilustración curiosa de este panorama está en la expresión popular chocar ¿jogar conversa fora' (charla banal?) que estaría ocupando el lugar de 'bater un papo' (chatear) o sea una conversación despreocupada que ocurriría en situaciones de ocio en las fugaces 'horas alegres' (happy hours). Esta, en general, tiene una función de distracción, fuera de los contextos usualmente opresivos del mundo competitivo del trabajo, antes de que las personas en edad económicamente activas vuelvan a sus residencias. Y, también, lejanas a las preocupaciones de las conversaciones que pretenden 'agregar valor' en el mundo de la productividad, tal como acostumbra acontecer en los contextos laborales. Son palabras que no pueden ser olvidadas, jogadas fora, pues si así sucediese, podrían comprometer la marcha y sobre todo lo lucrativo del negocio.

¿Cómo lidiar con este panorama y desmontar una retórica que moldea el discurso de primacía de la acción y que acusa la actividad reflexiva como irrazonable? Como veremos, hay un equívoco al designar la crítica conceptual como discusión sobre 'sexo de los ángeles' y, de esta forma, justificar no entrar en la discusión acerca de los presupuestos condicionantes de categorías que pueden servir para naturalizar y sustentar una ideología liberal y neoconservadora globalizada, y su capacidad de producir desigualdades, injusticias y aun más culpabilizar a sus víctimas. De acuerdo con Foucault (1979), una teoría consiste en una práctica que sirve de instrumento de lucha para esta tarea.

Una posibilidad inicial para responder a la acusación de bizantinismo, sería usando una justificación levemente irónica, una apelación alegórica. Es importante saber, sí, de los ángeles, pues ellos son seres que actúan como intermediarios entre el Todopoderoso y los seres humanos. En otras palabras, tal vez no hubiese ocurrido la crisis económica del 2008 si existie- 
sen entidades que acompañen los flujos de poder entre los hombres influyentes, que afectan a los desposeídos; si hubiese entes que pudieran monitorear a los altos funcionarios del sistema financiero norteamericano en las equivocadas decisiones que la causaron. Estos seres serían ángeles de la guarda de las poblaciones desprotegidas que verificarían las acciones del banquero para protegerlos.

Pero, si Dios está saliendo progresivamente de las ecuaciones humanas, dominadas ahora por la tecnociencia, los ángeles estarían perdiendo su empleo de mensajeros. Aun así Michel Serres (1995) destaca que ángel (del latín tardío ángelus - mensajero de Dios-, a su vez derivado del griego aggelus -mensajero) (Hpuaiss, 2001) permite simultáneamente comprender el funcionamiento de las cosas, de los seres humanos y de los objetos y develar la dimensión moral en cuestión - un ángel independiente de su sexo, hace una mediación entre estos dos mundos. Algo crucial en los días de hoy.

Ahora, cabe seguir a Fourez (1995) al mencionar las formas de descalificar una perspectiva de teoría crítica. Para reflexionar sobre este tipo de preguntas, importa discriminar dos tipos de intereses en la vida humana. Uno, particular, relativo a los modos como cada persona lidia con su propia subsistencia, su inserción en la vida laboral con finalidades económicas o con la cuestión de ubicarse como un profesional que debe ser remunerado en el mundo del trabajo y también como un agente consumidor. En este contexto, se puede llevar la vida de tal forma que la 'reflexión filosófica' no tenga relevancia alguna.

Pero hay otro nivel más amplio de intereses relacionados con las cuestiones referentes al sentido de la existencia humana y a la historia de la humanidad, que indaga sobre qué es ser humano, cómo deben organizarse las sociedades humanas. Incluye también cuestiones éticas: definir qué es el bien -individual o colectivamente- $y$, sobre todo, como pensar tales aspectos en términos de dignidad.

Entonces, podemos considerar dos enfoques básicos en la actividad científica: una visión específica de carácter instrumental -que se refiere esencialmente al levantamiento me- todológicamente confiable y fidedigno de datos y a la correspondiente aplicación correcta de protocolos y diseños de investigación- y una perspectiva extensa -que corresponde a las múltiples actividades más allá del rigor científico: estrategias de búsqueda de financiamiento, gestión de relaciones entre grupos académicos, comunicaciones entre pares, formas de publicar artículos en revistas consagradas.

La producción científica se constituye, como se ha mencionado en el desarrollo de este libro, también en una producción simbólica como elementos ideológicos. Su indiscutible eficacia instrumental puede camuflar su dinámica ideológica. Es fundamental preguntarse por las señales de afinidad entre las perspectivas universalizantes de la cultura tecnocientífica y las propuestas globalizantes del liberalismo económico.

Los discursos ideológicos incluyen una representación del mundo que tiene como propósito: motivar a las personas en una determinada dirección, legitimar ciertas prácticas, enmascarar una parte de los puntos de vista y criterios utilizados. Se puede pensar en dos tipos de camuflaje ideológico: 1) aceptables -cuando las representaciones de la construcción científica pueden ser perfectamente rastreables, los elementos que influyen en la construcción de los conceptos pueden ser localizados y cuando hay conciencia de las decisiones tomadas en la práctica; 2) inaceptables -cuando los indicios de la historia coyuntural de construcción de los conceptos salen de escena, y esos conceptos básicos se naturalizan como 'objetivos'. Importa enfatizar que las representaciones ideológicas se pueden instituir más allá de las intenciones de aquellos que las proponen Foruez, 1995).

Es preciso también estar atento a la alerta de Agamben (2005), al llamar la atención sobre la 'museificación' del mundo. Originalmente, un museo era un templo, un local de culto para las musas, las ninfas de los bosques que fueron transformadas en divinidades en la mitología griega, responsables por las artes y las ciencias. En la actualidad se han vuelto un lugar para turistas, en general, para que aprecien exhibiciones de reliquias históricas y obras de artes consagradas. De acuerdo al patrón de vigilancia 
aplicado en estos contextos, los visitantes son controlados con la finalidad de prevenir riesgos de vandalización, robos o uso de imágenes indebidamente fotografiadas por visitantes considerados incivilizados 0 indisciplinados. Los Souvenirs deben ser adquiridos en los propios locales de los museos. Porque cada vez más los museos asumen características de locales de marca, constituyéndose en puntos de venta para el consumo de recuerdos. Como acostumbra ser intenso el estímulo de la experiencia estética, esto puede llevar al consuno de reproducciones, miniaturas, álbumes, camisetas, llaveros, etc.

Una museificación agambiana del mundo se refiere a una retirada progresiva de las matrices simbólicas que tenían relevancia para la vida humana -artes, religión, filosofía, ideas de naturaleza y también, política. En este caso, el 'museo' debe ser entendido como una dimensión aparte a la cual fue enviado aquello que en el pasado era considerado fundamental para la civilización humana, pero que ya dejó de serlo. Como mencioné, hace ya tiempo que el museo perdió la dimensión de 'templo', para volverse salón de exhibiciones y espectáculo de objetos que preservan su poder estético, su importancia histórica, pero no tienen posibilidades de ser usados. Pueden apenas ser apreciados en el transcurrir de la experiencia vivida en aquel contexto resguardado, pero han perdido todo significado fuera de allí. ¿Será el museo el destino del pensamiento filosófico, como un anticuado templo donde solamente habría una posibilidad diletante de conocer aquello que un día fue preocupación de pensadores, musas y ángeles?

De cierta forma se puede sugerir que las ideas de Agamben parecen alinearse con el diagnóstico de Max Horkheimer (1975), uno de los representantes de la Escuela de Frankfurt, quien en 1937, al asumir la crisis de la teoría crítica en función del hecho de que las presiones que conducen a la barbarie no se oponen a la racionalidad, inclusive se confunden con ella. $Y$ también, se desdoblan de ella. Una vez que el pensamiento crítico no puede echar mano de la razón por configurar sus conceptos a partir de ella y por hacer referencia a nociones racionales de verdad, libertad y justicia, acaba cayendo en una contradicción al criticar los excesos de la razón.

El vínculo iluminista de la teoría crítica con el análisis de la cultura y de la sociedad moderna a partir de la razón parece ser indisoluble. Simultáneamente, no es posible olvidar que es en esta concepción de razón y en las instituciones construidas basadas en ellas donde se localiza el embrión de su locura (Horkheimer, 1975).

En nombre de una razón que se confunde con los dictámenes corporativos del capitalismo globalizado, se descartan inmunitariamente las narrativas alegóricas y simbólicas, que buscaban protegernos de nuestro propio potencial humano de transitar por la locura y por la barbarie. Más aún: es preciso estar atento a la tendenciosa dimensión del racionalismo a la modelación de las personas y las sociedades. Esto se da a partir de teorías simplificadoras de lo que es definido como comportamiento humano, que así, puede ser sometido a planes de gestión racional de deseos y voluntades.

Costumbres, hábitos y sentimientos más arraigados pueden ser configurados como elementos indeseables, por no permitir las exigencias de obsolescencia que la producción y el consumo acelerado, mercados globalizados demandan. Tales aspectos tienden a ser transformados en obstáculos y limitaciones que deben ser trascendidos en nombre de formulaciones racionalistas con vista a alguna idea subyacente de redención.

Cabe señalar que Bauman (2007b, 2008a) rechaza vigorosamente la acusación de bizantino de que la actividad del pensamiento está desprovista de pertinencia. Esto aparece en varios momentos de su obra, pero, sobretodo en los epílogos de Vida Líquida (2005) y Medio Líquido (2006), que destaca el papel del pensamiento para enfrentar los tiempos sombríos y el miedo en nuestra espantosa época. En ambos, el sociólogo polaco menciona la teoría crítica de la Escuela de Frankfurt, utilizando, incluso, un agregado al epílogo de Medio Líquido al indicar en el cierre del libro que se trata de "una conclusión inconclusa para los que pueden preguntar lo que corresponde hacer" (Bauman, 2008a:208). Y también, indica en ambos textos que el hecho de que Adorno negara en la práctica el aprecio que le es generosamente 
dispensado por los representantes de la ciencia positiva y por los académicos. El ejercicio de una práctica y los resultados de una acción no son elementos suficientes por sí solos, alejados de una perspectiva teórica crítica, para salvaguardar la posibilidad de cambio que se hacen imperiosos.

No parece ser más posible revertir de la razón ya recorrida por la civilización. Por tanto hemos de llamar la atención por la dimensión ideológica subyacente en muchos abordajes catastrofistas que se llaman racionales. Paradojalmente, estos se apartan del esclarecimiento sobre los riesgos y amenazas que pueden caer sobre nosotros como si estuviésemos involucrados en una atmósfera paradojal de un 'neooscurantismo ilumnista'.

Siguiendo una vez más a Bauman (2010), la aparentemente interminable trayectoria de la ciencia, coloca siempre nuevas encrucijadas a ser superadas, otros desafíos a ser vencidos, otros misterios a ser abordados y, si es posible, revelados. Y así, delante de las incertidumbres que no cesan en este caminar, inevitablemente siempre cae una atmósfera amedrentadora sobre nosotros, participantes cautivos de esta jornada.

Como sugiere Virilio (2010), muchas veces criticado por un supuesto pesimismo, es preciso resistir a la intensificación creciente de presiones alarmistas que participan de la creación de un sentimiento apocalíptico que mina cualquier propuesta emancipatoria solidaria, desmovilizadas por el frenesí individualista que anima. Si hay indicios de catástrofe en el horizonte (asumiendo que no parece haber muchas dudas sobre el calentamiento global, quedando solo saber en qué grado esto sucederá), es preciso que sean tratados a través de una nueva relación entre la razón y la seguridad., que no implique obligatoriamente regímenes insanos mal disfrazados de vigilancia y control vinculados necesariamente a la ampliación de los medios de opresión.

Aquí, vale la pena mencionar una respuesta chistosa de Bauman en un debate ya citado en Barcelona en el 2005, frente a la crítica de Tariq Ali de que no debemos juntar en una depresión total y absoluta que nos paralice frente a las realidades de los refugiados, favelados 0 parias del mundo globalizado. Realidades que son heterogéneas y, además de esto, Bauman parece no considerar que hay movimiento politizados de grupos sociales desprotegidos y de resistencia -como aquellos que resistieron las tentativas de retirar al presidente Chávez del gobierno venezolano.

Al responder, el sociólogo polaco dice que frecuentemente escucha esa misma crítica: la de ser pesimista. Así, define al optimista como aquel que cree que este es el mejor de los mundos posibles. Y el pesimista, aquel que no cree que el optimista pueda tener razón. De acuerdo con este criterio, Bauman (2008a), dice no ser ni lo uno, ni lo otro, porque cree que el mundo puede ser diferente, pero, para que esto suceda, es preciso asumir que existen serios problemas que piden movilizar fuerzas.

Sin pesimismo, Bauman (2008a:208,209) no duda en retirar a los intelectuales de la torre de marfil y las disputas sobre el sexo de los ángeles, al definirlos como "personas que continúan creyendo que el último propósito del pensamiento es hacer el mundo mejor del que encontraron". Tal tarea está inapelablemente vinculada a la relevancia de la permanencia de la idea de emancipación en la agenda del pensamiento crítico delante de "un mundo indisculpablemente enemigo de la humanidad". El pensamiento crítico debe sustentar el acto de coraje que se tornó en una mantención de las esperanzas de cambio enfrente de la ideología que intenta convencernos que vivimos en el mejor de los mundos posibles.

Cabe ahora, al final, volver a la propuesta de resistencia indicada en la presentación. En el caso de la gestión hiperpreventiva de los riesgos mediante cálculos racionales, tenemos que tener en cuenta que nuestros cuerpos-riesgo, son configurados por determinados procesos de producción de subjetividad. Si encaramos los riesgos como elementos de descripción y explicación objetiva por la cultura tecno científica, esos riesgos sustentarán los presupuestos metafísicos que nos mantiene cautivos en contextos que reducen nuestra subjetividad a una gestión racional de estilos de vida, hábitos y comportamientos. Estas formas de gestión se presentan como una posibilidad adecuada para lidiar con las amenazas reales e imaginarias que 
no cesan de acosarnos, sin conseguir éxitos en protegernos de la ansiedad que acompaña la sensación de incertidumbre que nos asedia simultáneamente.

Para enfrentar esta cuestión, es necesario aceptar, como punto de partida, que tal concepción de la gestión de riesgos posee límites y, también, nos coloca merced de un régimen de sumisión a una idea insustentable de control y regulación. Al mismo tiempo, instituye nuestra pertenencia a procesos que establecen y definen nuestros modos de subjetivación en los cuales el miedo se instala como una presencia insistente.

Según Pedro y Chevitarese (2005), una posibilidad de resistencia ocurre mediante la afirmación de otros modos de subjetivación que no impliquen tan sólo un rechazo al control. Pero, sí, la garantía de atención a otras formas de vida que amplíen los formatos previsibles propuestos por las directrices de gestión racional.

No deben quedar dudas que no se trata aquí de una ingenua apología de la exclusión sumaria de situaciones en que innegablemen- te la racionalidad técnica presenta resultados satisfactorios. Entretanto, es esencial procurar otros arreglos y lugares donde se pueda actuar, contestar y resistir en el interior de nuestra cultura, bajo la forma de 'utopías reales', que podrían ser llamadas 'heterotopías' siguiendo a Foucault (1986). Ahí sería posible viabilizar nuevos formatos para pensar y lidiar con los riesgos mas allá de las ambigüedades y la opresión producida por los modelos vigentes de aversión/atracción a ellos.

Por tanto, no cabe abdicar del derecho de ejercer la teoría como una práctica activa de lucha, aunque sea cada vez menos bienvenida en el ámbito académico, delante de la primacía de los modos dominantes de productividad. Práctica crítica con vistas a hacer de este mundo 'menos enemigo de la humanidad', al apuntar a las locuras de la razón que proliferan en el afán racional de la gestión, control y regulación de riesgos, sin que sea considerada como equivalente a las bizantinas discusiones sobre el sexo de los ángeles. 